\title{
The New Fertility Policy and the Actuarial Balance of China Urban Employee Basic Endowment Insurance Fund Based on Stochastic Mortality Model
}

\author{
Yuantao Xie $\mathbb{D}^{1},{ }^{1}$ Xinzhu Zhang, ${ }^{1}$ Huijuan Lv, ${ }^{1}$ and Xiaojing Guo $\mathbb{D}^{2}$ \\ ${ }^{1}$ School of Insurance and Economics, University of International Business and Economics, Beijing 100029, China \\ ${ }^{2}$ Zhongtai Securities, Beijing 100032, China \\ Correspondence should be addressed to Yuantao Xie; xieyuantao@uibe.edu.cn and Xiaojing Guo; 942005285@qq.com
}

Received 15 March 2020; Accepted 21 April 2020; Published 14 May 2020

Guest Editor: Wenguang Yu

Copyright (c) 2020 Yuantao Xie et al. This is an open access article distributed under the Creative Commons Attribution License, which permits unrestricted use, distribution, and reproduction in any medium, provided the original work is properly cited.

\begin{abstract}
This study aims to investigate the impact of China's new fertility policy on the actuarial balance of its Urban Employee Basic Endowment Insurance (UEBEI) fund, with stochastic mortality model included to address the longevity risk. Combined with the latest UEBEI policy, this paper constructs an actuarial balance model and introduces the growth rate of wage, the age of employment and the age of retirement, the rate of payment, the rate of replacement, the annual rate of pension adjustment, and the population in terms of age into the model, which arise from the rate of payment, average wage, and personal and social factors. This study uses the sixth population census data by age group and gender to employ empirical analysis. The sensitivity analysis of China's basic pension insurance fund balance is made. It is concluded that the increase in the growth rate of wage caused by social factors, the increase of fund investment returns, the delay of retirement, and the increase in the fund collection rate are all conducive to the sustainability of the UEBEI fund.
\end{abstract}

\section{Introduction}

Pension fund gap is one of the most urgent and important problems that China's pension system has to face. As early as 2014, the shortage of China's pension fund has begun to show gaps in about 23 provinces. According to "the 2016 Annual Report on the Development of Social Insurance in China" prepared by the social security management center of the Ministry of Human Resources and Social Security (http://www.mohrss.gov.cn/SYrlzyhshbzb/dongtaixinwen/ buneiyaowen/201711/t20171124_282237.html), many provinces are suffering from gap in the current period, including Heilongjiang, Liaoning, Hebei, Jilin, Inner Mongolia, Hubei, and Qinghai. In 2016, Heilongjiang's pension gap reached 23.2 billion yuan, and Guangzhou's gap was 1.2 billion yuan. In 2018, the deficit gap of social security fund reached 450.4 billion RMB. As a matter of fact, the deficit gap of pension fund accounts for $70 \%$ of the deficit gap of social security fund (Ren et al. [1]). According to the World Bank, if China does not change its current pension insurance operation model, by 2065, the revenue and expenditure gap of China's pension insurance fund will reach 9 trillion yuan (World Bank [2]).

Freedman and Zhang [3] also believe that if the pension gap in the future is only fully covered by the pension fund, then the assets will be exhausted in about 2036. If we want the Pension Reserve to fully cover the pension gap, the annual growth rate will be as high as $30.5 \%$ (Tang et al. [4]).

The Urban Employee Basic Endowment Insurance (UEBEI) fund is an important part of pension fund and an important pillar to protect people's livelihood and maintain social stability. According to Figure 1, it can be seen that the revenue, expenditure, and balance of the UEBMI fund are still on the rise at present. However, we can also see that the growth rate of the cumulative balance has declined from $52.55 \%$ in 2002 to $-0.06 \%$ in 2019 . In fact, once there is a 


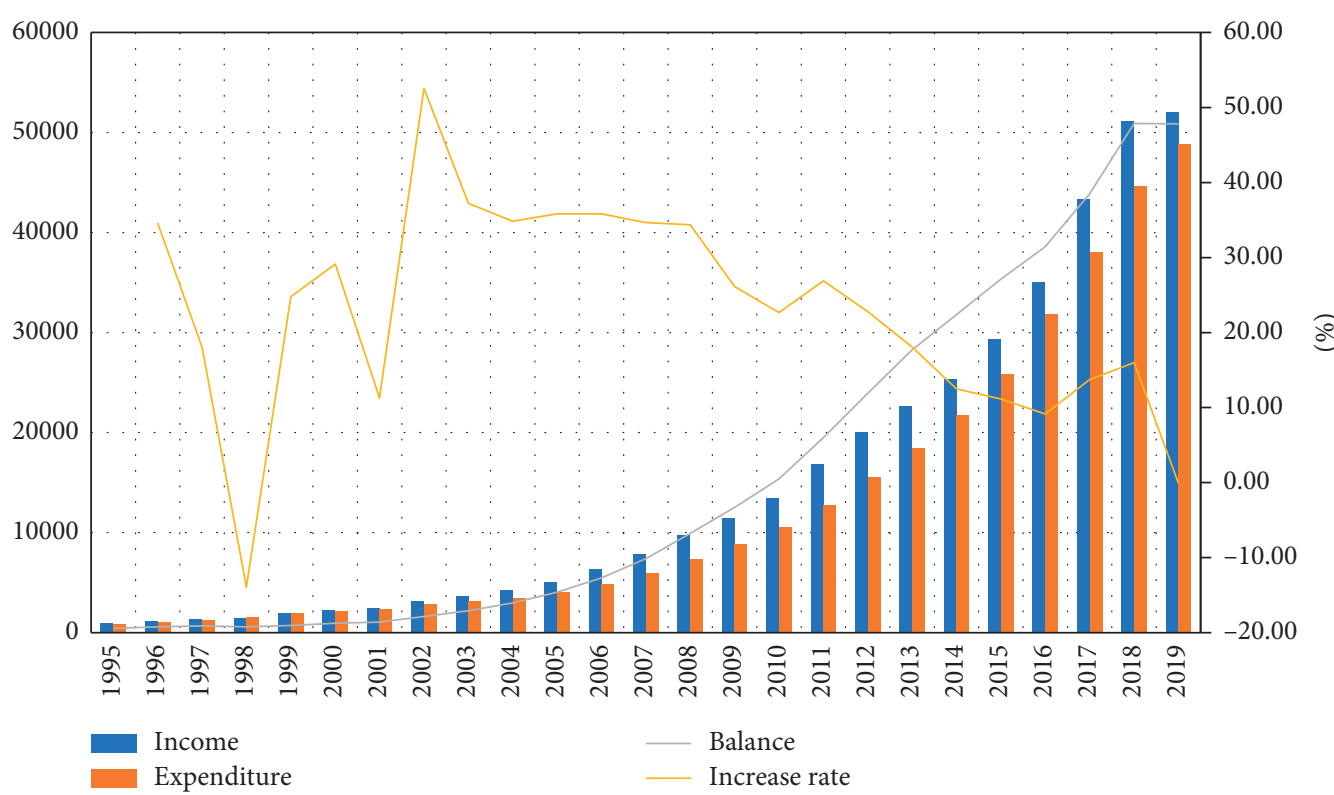

FIGURE 1: Revenue, expenditure, and balance of China's UEBEI fund (unit: 100 million RMB). Source: CEI net statistics database, http://202. 204.164.23:91. Accessed on Feb. 18 ${ }^{\text {th }}, 2020$.

fund gap in a province, the state and the province will use finance to subsidize the gap. After eliminating the financial subsidy from the fund income, the gap will be much higher than the figure on the chart.

The UEBEI fund has been affected by the problems associated with its demographic structure, such as low fertility and population aging. An increase in the aging population in the future may lead to a sharp increase in expenditure, and given the pay-as-you-go features of the UEBMI system, there might also be a huge deficit. According to the estimation results of "China's National Balance Sheet" prepared by the Chinese Academy of Social Sciences (http://ie.cass.cn/ achievements/academic_works/201812/t20181227_4801661.

$\mathrm{html}$ ), the population over 60 years of age will reach $19.3 \%$ by 2020 , and it will reach $38.6 \%$ by 2050 ; the dependency ratio of China's employee pension insurance will be $2.94: 1$ in 2020, and it will drop to $1.3: 1$ by 2050 . There will be a fund gap in UEBEI nationwide by 2023 if we continue to implement the existing pension system; the accumulated balance of endowment insurance will be exhausted by 2029 .

The UEBEI gap brings great pressure on the national finance. As of 2016, Shanghai's municipal financial revenue has reached a total of 17 billion yuan. According to the "China Pension Development Report 2019" compiled by the Chinese Academy of Social Sciences (http://www.cisscass. org/yanjiucglist.aspx?classid=1, http://mini.eastday.com/ bdmip/190225130456273.html\#), the transfer payment subsidies to the UEBEI reached 227.2 billion yuan in 2019, and the accumulated financial subsidies reached 1.2526 trillion yuan. According to "Resolving the Medium- and LongTerm Risks of National Assets and Liabilities" (http://misc. caijing.com.cn/chargeFullNews.jsp?id=111886697\&time $=2012$ $06-11 \& \mathrm{cl}=106)$, the gap of the UEBEI fund will reach more than $20 \%$ of the fiscal expenditure in one year by 2050 .
The government hopes to alleviate the problem of population aging by raising the birth rate, thereby relieving the pressure on pension payments. The eighteenth meeting of the Twelfth National Congress passed the decision on the revision of the population and family planning law, which means the coming of the era of universal two children. The state hopes to alleviate the problem of population aging by increasing the birth rate, so as to relieve the pressure of pension payment. In this context, this paper seeks to address the issue of increasing payment pressure on pension funds in the future. At present, there is not much research on the management of the provincial endowment insurance fund. In particular, there is not enough quantitative research on actuarial modeling of pension funds, actuarial balance, and financial sustainability. Under this background, this article seeks the solution of the problem of increasing pressure of basic pension insurance fund payment in the future. This article focuses on the management of the UEBEI fund and proposes reasonable and practical policy proposals as a timely solution to the development dilemma by using figures and suggestions.

\section{Literature Review}

There have been many studies in the literature on the revenue and expenditure balance of the UEBEI fund. Some scholars consider the issue from the perspective of the fund's expenditure. They hold the belief that population aging will lead to a rapid increase in UEBEI expenses. For the quantitative analysis of longevity risk, a good idea is to model mortality as random. The model of stochastic mortality has more advantages in the study of population structure. The classic model is Lee-Carter model (Carter and Lee [5]), which is a very influential model because of its simplicity and high accuracy. Renshaw and Haberman [6] improved the 
Lee-Carter model and established the R-H model, which could model and analyze the cohort effect and period effect of the specific age at the same time. In addition, the more famous model in academic circles is the age-period-cohort model (APC model) (for example, Reither et al. [7]). Hainaut [8] studied the general features of multifactor Lee-Carter models, with switching regime time components, to combine population structure with prices of life and death insurances, applying to fit 2-dimension, 2-state model to the French population. Some scholars have expanded the model; for example, Bell [9] extended it to the multilevel APC model. To deal with the longevity risk and to get better pricing results for annuity and pension, three British scholars, Cairns et al. [10], first proposed a CBD model of two-factor mortality in the form of logistic, which was especially used to predict mortality for the elderly. Cairns et al. $[11,12]$ then quantitatively compared the current influential models based on the mortality data of the UK, Wales, and the United States. After that, they analyzed 8 random mortality models and evaluated them qualitatively and quantitatively according to the historical data. Finally, the results of 6 models were found to be pretty good, and some suggestions on the model evaluation methods were given. Since then, the improvement and practice of CBD model, APC model, and Lee-Carter model have been continuing. Hainaut [8] used an adjustable death process to vary the variables related to time, thus constructing a multiple Lee-Carter model to analyze the population divided by gender in France from 1946 to 2007. Carfora et al. [13] discussed the comparison of models. Chernyavskiy et al. [14] expanded the traditional APC model to include quadratic age, period, and cohort terms and introduce stratum-specific random effects as well to find a unified methodology for the analysis of multiple strata (see also Xie and $\mathrm{Li}$ [15]). Basnayake and Nawarathna [16] used the Singular Value Decomposition (SVD) approach for estimating the parameters of Lee-Carter model and the Autoregressive Integrated Moving Average (ARIMA) time-series model for forecasting the mortality values to fit and forecast the mortality rate of Norway. Giacometti et al. [17] compared the performance of the Lee-Carter model and an AR(1)-ARCH(1) model with respect to forecasting age-specific mortality in Italy.

Under the new birth policy, changes in population structure and scale will predictably affect the actuarial balance of pension funds. Zhu and Yang [18] incorporated birth, infant mortality, and mortality into Leslie matrix, applying Leslie matrix grey forecasting model to predict population. Xie et al. [19] used Leslie model applicable to universal two-child policy for analysis and prediction of the population of different ages.

Some scholars also measure the sustainability of the UEBEI funds through actuarial balance; for example, Mircea et al. [20] developed some models for mortality rates and pricing considering the longevity risk; they also expanded some models for the securitization of longevity bonds or loans to increase the sustainability of pension funds from the perspective of longevity risk (Mircea et al. [20]; Lin and Tsai [21]; Yu et al. [22]). Metzger [23] analyzed the medium-term sustainability of the Swiss old-age pension scheme by estimating a "Swedish" actuarial balance sheet, which compares pension liabilities with the explicit and implicit assets of the pension scheme. Meyricke and Sherris [24] assess the costs of longevity risk management using longevity swaps compared to costs of holding capital under Solvency II (Meyricke and Sherris [24]). Bosnjak [25] for the first time made projections of dependency ratio of pension and disability insurance fund of Republic of Srpska using the actuarial projection technique. Belolipetskii and Lepskaya [26] specified eight factors such as the mortality rate and financial indicators as random variables to calculate the probability of ruin of a pension fund on a finite time interval based on the standard Cramer-Lundberg model.

In China, Luo et al. [27] established the models of Population Prediction and the Basic Old-Age Insurance Fund's payments and emphatically considered the influence of the demographic change on the balance of revenue and expenditure model. Therefore, the population urbanization rate and the population birth rate factors were added to the population forecasting model, which showed that improving the birth rate and delaying the retirement will be helpful to the balance of China's basic pension insurance in the future (see also Yu et al. [28]). Wang et al. [29] focused on the influence of "comprehensive two-child" policy and delayed retirement policy on the fund balance of urban workers' basic old-age insurance; they found that the adjustment of fertility policy and retirement policy could postpone the beginning of short-term and long-term pension fund deficits to 2053 and after 2060, respectively. Cong and Jin [30] analyzed the long-term balance of pension fund from the perspective of contribution mechanism. The previous literature mainly used the traditional model to analyze the actuarial balance, and the application of the stochastic mortality model (for example, He and Liu [31] formulated a state-space framework and used the Kalman filtering technique to estimate the joint model of the fitting and forecasting stages of traditional CBD method) will be more fully analyzed in the actuarial equilibrium analysis. Wang and Huang [32] used Bayesian information criterion and likelihood ratio test on several popular stochastic mortality models and considered that CBD model had the best fit for Chinese data, and the impact of longevity risk on the gap of individual account fund in China was studied by using CBD model. Yuan and Pan [33] predicted the mortality rates from 2014 to 2050 and classified them by gender and age based on the Lee-Carter model. Cui et al. $[34,35]$ analyzed it from the view of income mobility, tax burden, and dynamic equilibrium of income distribution.

Lots of the researches on the pension funds start with the analysis of the influencing factors. Raising the retirement age may quickly entail the least political cost to get a great shortterm budgetary effect by setting a variety of reform scenarios (Meyricke and Sherris [24]; Mircea et al. [20]), but reforms neglecting the interactions between the social security and the labor market are likely to fail. Zeng et al. [36] evaluated the effects of extending the retirement age in terms of fertility pattern and population structure by gender and workers categories. For more Chinese researches, see Zhao et al. [37]. Abdessalem and Cherni [38] developed a general 
equilibrium overlapping generations' model to evaluate the effects of different pension reforms: contribution rate increase, pensions' level reduction, the rise of the retirement age, and finally the introduction of a complementary fully funded system. Müller and Wagner [39] analyzed the impact of pension funding mechanisms on the solvency situation, including surplus distributions and remediation measures, and found that insurers and pension funds will profit from a cautious surplus distribution policy.

By establishing the actuarial model and using the stochastic mortality model to predict the population structure, this paper makes an empirical analysis on the balance of income and expenditure of the endowment insurance fund and the gap of funds in China by combining the real wage growth rate and the pension replacement rate. Through the study of the establishment and reform of the endowment insurance system in OECD countries, we compare the differences of that between OECD countries and China to find what can be used for reform in China. Under the background of population aging, this paper studies the financial balance of China's UEBEI fund in terms of actuarial science. At the same time, the CBD stochastic mortality model is introduced for the mortality forecast to get a better prediction than the life table.

This study explores the issue of the change in the fertility policy on the balance of China's UEBMI fund. This study establishes an actuarial model to predict the population structure based on the birth pattern under the second-child policy. It considers factors such as the actual wage growth rate and the replacement rate of pensions in China and conducts an empirical analysis of the balance of revenue and expenditure, fund gap, and other issues of China's pension funds. Overall, this paper studies the financial balance of China's pension fund from the point of view of actuarial aging under the background of population aging to address the longevity risk.

\section{Methodology}

Prior to the prediction of the dynamic balance of the UEBMI fund, we first need to predict the population structure under the two-child policy. Therefore, this paper adopts a twostage research method. The first stage involves predicting the population structure under the universal two-child policy, and the second stage uses the predicted population structure to explore its impact on the balance of the UEBMI fund. In this study, the UEBMI refers to employees working in cities, including those with urban hukou, as well as those with rural hukou but working in cities. Therefore, the whole sample in the population analysis is adopted to examine the primary issue in this study.

3.1. Methods of Forecasting the Population Structure. It is assumed that the effect of migration is not taken into account, and no major natural disasters or wars will occur during the predicted time period in the future. That is, the population will change smoothly. Considering the corresponding mortality rate, the total number of $x$-age groups that can survive to the next year can be expressed as

$$
N_{x+1}(t+1)=\left(1-d_{x}(t)\right) \times N_{x}(t),
$$

where $N_{x}(t)$ is the total number of people aged between $x$ and $x+1$ in the year $t$ and $d_{x}(t)$ is the death rate of $x$-age groups in a year $t$.

The number of newborns in the year $t$ should be

$$
N_{\text {newborn }}(t)=\sum_{x_{i}=x_{1}}^{x_{i}=x_{2}} b_{x_{i}}(t) \times \delta_{x_{i}}(t) \times N_{x}(t) .
$$

Among them, $b_{x_{i}}(t)$ represents the fertility rate of women in $x_{i}$-age groups in the year $t, x_{i} \in\left[x_{1}, x_{2}\right]$, and $\delta_{x_{i}}(t)$ represents the female ratio of the total population in $x_{i}$-age groups in a year $t$.

Suppose $d_{00}(t)$ is the $t$-year neonatal mortality rate; then the number of newborns in the year $t$ who can survive to the next age group is

$$
N_{1}(t+1)=\left(1-d_{00}(t)\right) \times\left(1-d_{0}(t)\right) \times N_{\text {newborn }}(t) .
$$

Let $B_{x_{i}}(t)$ be fertility pattern of childbearing women, and $\sum_{x_{i}=x_{1}}^{x_{i}=x_{2}} B_{x_{i}}(t)=1$. Suppose $b_{x_{i}}(t)=\beta(t) \times B_{x_{i}}(t)$, where $\beta(t)$ is the total fertility rate in a year. Substitute into equation (3); that is,

$$
N_{1}(t+1)=\left(1-d_{00}(t)\right)\left(1-d_{0}(t)\right) \sum_{x_{i}=x_{1}}^{x_{i}=x_{2}} \beta(t) B_{x_{i}}(t) \delta_{x_{i}}(t) N_{x}(t) .
$$

Since $\left(1-d_{00}(t)\right),\left(1-d_{0}(t)\right)$ and $\beta(t)$ are irrelevant to $i$, so let $\sum_{x_{i}=x_{1}}^{x_{2}}\left(1-d_{00}(t)\right)\left(1-d_{0}(t)\right) B_{x_{i}}(t) \delta_{x_{i}}(t)=B_{x_{i}}^{\prime}(t)$; then,

$$
N_{1}(t+1)=\beta(t) \sum_{x_{i}=x_{1}}^{x_{2}} B_{x_{i}}^{\prime}(t) N_{x}(t) .
$$

The next year's population vector can be deduced as

$$
N(t+1)=L(t) \cdot N(t)+\beta(t) \cdot \Delta(t) \cdot N(t),
$$

where $N(t)=\left[N_{\text {newborn }}(t), N_{1}(t), \ldots, N_{w-1}(t)\right]^{T}$ is the population vector in the initial year and survival rate matrix and fertility rate matrix can be shown as

$$
\begin{aligned}
& L(t)=\left[\begin{array}{ccccc}
0 & 0 & \cdots & 0 & 0 \\
1-d_{1}(t) & 0 & \cdots & 0 & 0 \\
0 & 1-d_{2}(t) & \cdots & 0 & 0 \\
& \vdots & \vdots & \vdots & \vdots \\
0 & 0 & \cdots & 1-d_{w-1}(t) & 0
\end{array}\right], \\
& \Delta(t)=\left[\begin{array}{ccccccccc}
0 & \cdots & 0 & B_{x_{1}}^{\prime}(t) & \cdots & B_{x_{2}}^{\prime}(t) & 0 & \cdots & 0 \\
0 & \cdots & 0 & 0 & \cdots & 0 & 0 & \cdots & 0 \\
\vdots & & \vdots & \vdots & & \vdots & \vdots & & \vdots \\
0 & \cdots & 0 & 0 & \cdots & 0 & 0 & \cdots & 0
\end{array}\right] .
\end{aligned}
$$

Among them, $d_{x}(t)$ and $B_{x_{i}}(t)$ are not divided into different age group and gender, but the sixth population census is only divided by age group and gender; we use the Lee-Carter model for interpolation and then come to estimations of mortality and fertility pattern among different age group and gender: 


$$
\log \frac{d_{x}(t)}{1-d_{x}(t)}=A_{1}(t+1)+A_{2}(t+1)(x+t)+\varepsilon_{x}(t)
$$

where $\log \left(d_{x}(t) /\left(1-d_{x}(t)\right)\right)$ is log-normalized mortality odds ratio. $A_{1}(\cdot)$ and $A_{2}(\cdot)$ are period effect impact factors, which indicate that the mortality rate will change over time. $\varepsilon_{x}(t)$ is disturbance.

To predict the distribution of $A_{1}(\cdot)$ and $A_{2}(\cdot)$, we can model it as a random walk with a drift term:

$$
\left(\begin{array}{l}
A_{1}(t+1) \\
A_{2}(t+1)
\end{array}\right)=\left(\begin{array}{l}
A_{1}(t) \\
A_{2}(t)
\end{array}\right)+\left(\begin{array}{l}
d_{1} \\
d_{2}
\end{array}\right)+C\left(\begin{array}{l}
z_{1}(t+1) \\
z_{2}(t+1)
\end{array}\right),
$$

where $d_{1}$ and $d_{2}$ are the drift terms, $C$ is a constant upper triangular matrix, and $\left(\begin{array}{c}z_{1}(t+1) \\ z_{2}(t+1)\end{array}\right)$ is a two-dimensional standard normal random variable. The OLS estimation of the drift term is relatively easy to obtain:

$$
\widehat{d}_{i}=\frac{\widehat{A}_{i}(T)-\widehat{A}_{i}(1)}{T-1}, \quad i=1,2,
$$

The estimation of $C$ is as follows:

$$
\widehat{C} \widehat{C}^{\prime}=\left(\begin{array}{cc}
\widehat{\sigma}_{1}^{2} & \widehat{\sigma}_{12} \\
\widehat{\sigma}_{12} & \widehat{\sigma}_{2}^{2}
\end{array}\right),
$$

where

$$
\begin{aligned}
\widehat{\sigma}_{i}^{2}= & \frac{1}{T-1} \sum_{t=2}^{T}\left(\widehat{A}_{i}(t)-\widehat{A}_{i}(t-1)-\widehat{d}_{i}\right)^{2}, \quad i=1,2, \\
\widehat{\sigma}_{12}= & \frac{1}{T-1} \sum_{s=1}^{T-1} \sum_{t=1}^{T-1}\left(\widehat{A}_{1}(s+1)-\widehat{A}_{1}(s)-\widehat{d}_{1}\right)\left(\widehat{A}_{2}(t+1)\right. \\
& \left.-\widehat{A}_{2}(t)-\widehat{d}_{2}\right) .
\end{aligned}
$$

3.2. Methods of Forecasting the Balance of China's UEBEI Fund. First of all, we need to determine a few assumptions.

Hypothesis 1. Only the workers' payment is considered in the income model of the fund, but the government's financial subsidies are not included temporarily. Otherwise, the expenditures of fund are not used for management expenses, and so forth, as they are used only for the pension for the insured retirees.

Hypothesis 2. The inflation factor is not considered in this model.

The factors that affect the income of the fund are the number of insured workers, the contribution rate, the collection rate, the UEBEI coverage rate and the workers' salary level, and growth rate; the factors that affect the fund expenditure are the number of retirees insured, the wage replacement rate of the UEBEI, and annual pension adjustment rate.
3.2.1. Income Model. First, we establish the actuarial model of the UEBEI fund's income in years as follows:

$$
I(t)=C_{r} \cdot \sum_{x=\alpha}^{\beta-1}\left[\overline{W_{\alpha, 1}} \cdot\left(1+g_{1}\right)^{x-\alpha}\left(1+g_{2}\right)^{t-1} \cdot L_{x}(t)\right] \cdot b(t),
$$

where $C_{r}$ is the contribution rate of the UEBEI, $\alpha$ is the working age of employees, $\beta$ is the retirement age of employees, $\overline{W_{\alpha, 1}}$ is the average wage of employees aged $\alpha$ in the first year of measurement period, $g_{1}$ is the wage growth rate caused by personal factors, $g_{2}$ is the wage growth rate caused by social factors, $L_{x}(t)$ is the number of insured workers aged $x$ in year $t$, and $b(t)$ is the premium collection rate of the UEBEI. Suppose the workers covered in UEBEI are a fixed portion, which can be conducted from $N(t)$ by age $x$.

According to the annual basic pension insurance fund's income $I(t)$ and the fund yield $r$, we can get the accumulation value of the UEBEI fund income at the end of the forecast period $n$ as follows:

$$
I=\sum_{t=1}^{n} I(t) \cdot(1+r)^{n-t},
$$

where $n$ denotes the year number during measurement period.

Substitute formula (13) for $I(t)$; then we have

$$
I=\sum_{t=1}^{n}(1+r)^{n-t}\left\{C_{r} \cdot \sum_{x=\alpha}^{\beta-1}\left[\overline{W_{\alpha, 1}} \cdot\left(1+g_{1}\right)^{x-\alpha}\left(1+g_{2}\right)^{t-1} \cdot L_{x}(t)\right] \cdot b_{t}\right\} \text {. }
$$

3.2.2. Expenditure Model. The amount of the pension received by retirees is connected with the personal wage replacement rate. More specifically, the pension in the first year of retirement is the product of replacement rate and salary in the year prior to retirement. Let $\overline{W_{\alpha}(t-x+\alpha)}$ denote the average salary of employees aged $\alpha$ in year $t-x+\alpha$, that is, the average salary of one year prior to retirement for the employees aged $x$ in years $t-x+\alpha$. Then, the salary of one year prior to retirement for workers aged $x$ in years $t-x+\alpha$ is

$$
\overline{W_{\alpha}(t-x+\alpha)} \cdot\left[\left(1+g_{1}\right)\left(1+g_{2}\right)\right]^{\beta-\alpha-1},
$$

and we have the following equation:

$$
\begin{aligned}
\overline{W_{\alpha}(t-x+\alpha)} & =\overline{W_{\alpha}(1)} \cdot\left(1+g_{2}\right)^{t-x+\alpha-1} \\
& =\overline{W_{\alpha}(1)} \cdot \frac{\left(1+g_{2}\right)^{t-1}}{\left(1+g_{2}\right)^{x-\alpha}} .
\end{aligned}
$$

As a result, the UEBEI fund expenditure in year $t$ is

$$
\begin{aligned}
O(t)= & T_{i} \sum_{x=\beta}^{w} \overline{W_{\alpha}(1)} \cdot\left[\left(1+g_{1}\right)\left(1+g_{2}\right)\right]^{\beta-\alpha-1}\left(1+g_{2}\right)^{t-1} \\
& \cdot \frac{(1+k)^{x-\beta} \cdot P_{x}(t)}{\left(1+g_{2}\right)^{x-\alpha}}
\end{aligned}
$$


where $T_{i}$ is the wage replacement rate, $k$ is the annual pension adjustment rate, which shows that the pension increases with the retirement age, and $P_{x}(t)$ is the number of retired workers aged $x$ in years. Then the cumulative expenditure of the UEBEI fund at the end of the target test period is

$$
\begin{aligned}
O & =\sum_{s=1}^{n} O(t) \cdot(1+r)^{n-s} \\
& =\sum_{t=1}^{n}(1+r)^{n-t}\left\{T_{i} \sum_{x=\beta}^{w} \overline{W_{\alpha}(1)} \cdot\left[\left(1+g_{1}\right)\left(1+g_{2}\right)\right]^{\beta-\alpha-1}\left(1+g_{2}\right)^{t-1} \frac{(1+k)^{x-\beta} \cdot P_{x}(t)}{\left(1+g_{2}\right)^{x-\alpha}}\right\} .
\end{aligned}
$$

3.2.3. Actuarial Balance of the UEBEI Fund. Actuarial Balance of the UEBEI fund is

$$
\Delta E=I(t)-O(t)
$$

where $\Delta E$ is the cumulative balance; $\Delta E=0$ shows the UEBEI fund income and expenditure balance in year $t$. $\triangle E>0$ shows that the UEBEI fund current income is greater than the expenditure. $\Delta E<0$ shows that the UEBEI fund expenditure in the current year is greater than income. This model, combined with the partial accumulation of the UEBEI system in China, can better predict the income and expenditure of the UEBEI fund in the future.

\subsection{Parameter Setting}

3.3.1. Population Structure Parameters. Leslie population prediction model is used to establish a discrete matrix by gender and age to predict the population and population structure of the UEBEI in the future. Based on the population census data by age in China in 2010, we input the population data of different age group in 2010 to get $N(t)$. The resulting fertility matrix and survival matrix, both of which are regular matrices, are substituted into equation (6). Table 1 shows the data by age group and gender about population composition, fertility rate, and fertility pattern as of 2015 .

\subsubsection{Parametric Assumptions of the Actuarial Balance Model}

(1) Contribution rate $C_{r}$

The contribution rate represents the proportion of total endowment insurance paid by employees and employers to personal wages. According to the contents of the "decisions" published in 2005 and 2015 , the company contribution accounts for $20 \%$ and individual contribution accounts for $8 \%$. So, in this paper, we assume that the contribution rate $C_{r}$ is $28 \%$.

(2) Collection rate $b(t)$

The collection rate of endowment insurance is the rate of how many persons are covered in the endowment insurance. It reflects the collection enforcement of a national pension. In 1995, the contribution rate of Chinese endowment insurance was above $90 \%$, but it has been declining gradually in recent years. However, taking into account the fact that the national collection system will be gradually improved, the average collection rate of endowment insurance premiums for the target period, that is $b(t)$, here is set to be $85 \%$.

(3) The average wage level $\overline{W_{\alpha}(1)}$ and the growth rate of $g_{1}, g_{2}$

According to statistics on average wages and growth rates of Chinese workers from 2000 to 2014, we can get an average growth rate of $13.63 \%$ for workers' average money wages and $11.21 \%$ for real wages excluding price changes (according to the statistics released by the National Bureau of Statistics from 2007 to 2015, with the slowdown of China's economic development, the average wage growth rate of employees has exhibited a downward trend). In recent years, the rate of wage growth in China tends to slow down. Therefore, taking into account situations in last few years, this paper assumes that the actual rate of wage growth is $8 \%$. In addition, because the influence factor of wage increase includes personal and social factors, this paper assumes that the annual average wage growth rate $g_{1}$ caused by personal factors is $2 \%$ and that the annual average annual wage growth rate $g_{2}$ caused by social factors is $6 \%$.

Based on the assumed growth rate of $8 \%$, the average wage in 2015 can be calculated as $60,868.8$ yuan. From the actual situation, the wage of newly employed workers in China $\overline{W_{\alpha}(1)}$ is equivalent to $65 \%$ of the average social wage.

(4) Replacement rate $T_{i}$

The replacement rate of China's UEBEI system is set as $60 \%$, so this paper assumes that the basic pension insurance salary substitution rate $T_{i}$ of the retired workers is $60 \%$.

(5) Annual adjustment rate of basic pension $k$

The base of the basic pension plan for retirees will be adjusted as the average wage increases, but the increase should not be higher than $60 \%$ of the average wage growth in the previous year. Therefore, this 
TABLE 1: Population composition, fertility rate, and fertility pattern by age group and gender in 2015 .

\begin{tabular}{|c|c|c|c|c|c|c|}
\hline Age & $\begin{array}{l}\text { Average proportion of } \\
\text { childbearing women (\%) }\end{array}$ & $\begin{array}{c}\text { Births } \\
\text { proportion (\%) }\end{array}$ & $\begin{array}{c}\text { Fertility rate of } \\
\text { childbearing women } \\
(\% 0)\end{array}$ & $\begin{array}{l}\text { Fertility rate 1st } \\
\text { birth }(\% 0)\end{array}$ & $\begin{array}{l}\text { Fertility rate of } \\
\text { 2nd birth }(\% 0)\end{array}$ & $\begin{array}{l}\text { Fertility rate of } 3 \mathrm{rd} \\
\text { birth and above }(\% \circ)\end{array}$ \\
\hline $15-19$ & 10.18 & 3.03 & 9.19 & 7.99 & 1.12 & 0.08 \\
\hline $20-24$ & 13.54 & 24.05 & 54.96 & 40.17 & 13.39 & 1.41 \\
\hline $25-29$ & 16.89 & 40.59 & 74.31 & 41.55 & 28.80 & 3.96 \\
\hline $30-34$ & 13.62 & 19.95 & 45.31 & 14.98 & 25.42 & 4.91 \\
\hline $35-39$ & 13.19 & 7.93 & 18.60 & 4.63 & 10.96 & 3.01 \\
\hline $40-44$ & 16.14 & 2.80 & 5.37 & 1.85 & 2.45 & 1.07 \\
\hline $45-49$ & 16.44 & 1.65 & 3.11 & 1.25 & 1.23 & 0.63 \\
\hline Total & 100 & 100 & 30.93 & 16.43 & 12.30 & 2.21 \\
\hline
\end{tabular}

Source: the authors performed calculation based on the data released by National Bureau of Statistics, http://data.stats.gov.cn/easyquery.htm?cn=C01.

paper assumes that the adjustment level of basic pension for retirees is $60 \%$ of the average wage growth rate for employees; that is, the annual adjustment rate of basic pension $k$ is $4.8 \%$.

(6) Fund yield $r$

According to the announcement issued by the Council of Social Security Fund in 2015, the total investment income of the social security fund was 139 billion and 209 million yuan in 2014, and the yield reached $11.43 \%$, which was 9.43 percentage points higher than the inflation rate of the same period and also higher than the growth rate of the gross domestic product (GDP). From the establishment of the social security foundation to the end of 2014, the average annual rate of return on investment reached $8.36 \%$. In 2015 , the return of 1 trillion and 800 billion assets of the social security fund was $15.14 \%$. At present, in addition to the traditional investment channels such as fixed deposits, long-term bonds and stocks, futures, and other investment approaches traded publicly, Chinese social security fund also aims at some "offbeat investment" channels, including private equity, venture capital, leveraged buyout, and many other varieties, and has got good results, showing a good developing tendency of the insurance funds investment, so this paper assumes that the yield $r$ is $10 \%$.

(7) Employment age $\alpha$ and retirement age $\beta$

The survey data from the Ministry of Human Resources and Social Security shows that the employment age is generally around 20 to 22 but starts from 16. For convenience of calculation, this paper assumes that the age of initial employment for employees is 16. In China, according to the provisions of the law on retirement age, except for special circumstances, male unified retirement age is 60 , female workers' retirement age is 50 , and female cadres' retirement age is 55 . While taking into account the Chinese policy to postpone retirement age, possibly published in the future, our model sets the average retirement age for men and women $\beta$ as 57 . So, the average working length $\beta-\alpha$ is 36 years.
3.4. Research Limitations. Owing to data limitation, this study has made many strong but necessary assumptions. However, some strong assumptions are based on literature, for example, contribution rate, collection rate, the average wage level and the growth rate, replacement rate, annual adjustment rate of basic pension, and fund yield.

Although some of these strong assumptions regarding parameters have been relaxed by using factors analysis on the Balance of Revenue and Expenditure in the Model as shown in Section 4.3, some strong assumptions still exist due to data limitation. For example, the interest rate is constant during forecasting period, the demographic structure of the population participating in the UEBEI system is consistent with the demographic structure of the population in China, and the population of those insured consists entirely of those who are more than 20 years old. Nevertheless, all these assumptions are necessary and reasonable as the forecasting is conducted.

\section{Empirical Analysis}

4.1. The Estimation of Population System Covered by UEBEI. According to the population data from 1997 to 2019, the values of $\widehat{A}_{1}(t)$ and $\widehat{A}_{2}(t)$ can be obtained. Combined with formula (10), the drift term $\widehat{d}_{i}$ can be calculated. Then, according to formula (12) and formula (11), we can obtain $C$.

So, for this random walk model, we can estimate

$$
\begin{aligned}
\widehat{d}_{i} & =\left(\begin{array}{l}
\hat{d}_{1} \\
\hat{d}_{2}
\end{array}\right)=\left(\begin{array}{c}
-2.1762 \\
0.0018
\end{array}\right), \\
\widehat{C} \widehat{C}^{\prime} & =\left(\begin{array}{cc}
\widehat{\sigma}_{1}^{2} & \widehat{\sigma}_{12} \\
\widehat{\sigma}_{12} & \widehat{\sigma}_{2}^{2}
\end{array}\right)=\left(\begin{array}{cc}
123.1348 & 0.0224 \\
0.0224 & 0.00369
\end{array}\right) .
\end{aligned}
$$

So far, we can get random walk models for $A_{1}(t)$ and $A_{2}(t)$, and then we can get the estimates of $A_{1}(t)$ and $A_{2}(t)$ for every year until 2030, and using those estimates, future annual mortality curves can be obtained, and the age-specific mortality rate for people over 60 years of age can be calculated, as shown in Figure 2.

Figure 2 shows a total of 21 mortality curves. From the figure, we can get the following aspects of information: (1) the mortality rate is accelerating as the age increases; (2) mortality rate in future years is obviously lower than the current year; (3) the mortality rate gradually approaches one 


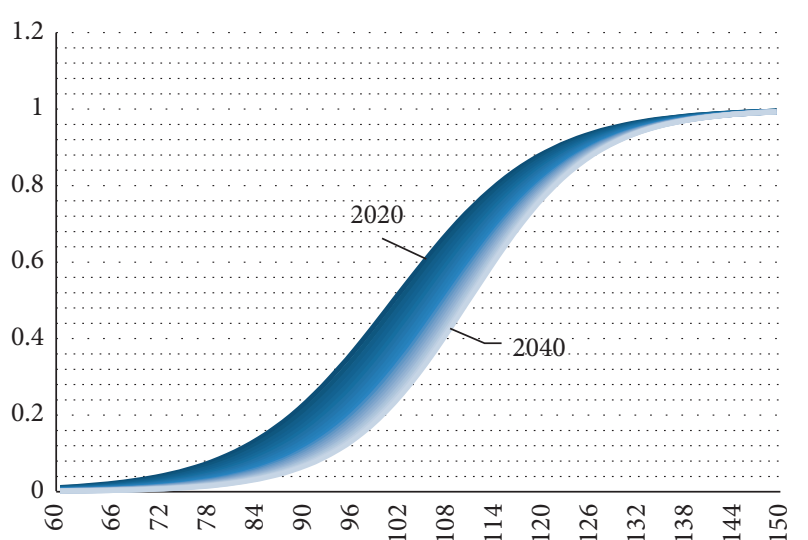

FIGURE 2: Estimated mortality probabilities for people over 60 years of age from 2020 to 2040 . Source: the authors performed calculation based on the model.

around 150 years of age, which shows a longevity risk. Meanwhile, at present, the insurance industry generally adopts 105 as the ultimate survival age. Previously, the study on gap of pension insurance annuity also generally adopted 90 as the ultimate survival age. The mortality rate estimated by CBD model is different from that obtained by actual statistics. Demographics are cut off directly at the age of 90 , and the CBD model can be used to estimate the mortality rate of people over 90 years of age.

In order to match the data analysis and let the data be more scientific and accurate, this paper adopts the 2010 census data as the population data. By substituting census data, we can deduce the annual population structure from 2010 to 2035. According to the insured structure of the UEBEI, the population structure of the UEBEI from 2010 to 2035 can be deduced. Figure 3 is the new birth policy predicted UEBEI covered population (note that the UEBEI covered population is different from the population. One will be covered in UEBEI after 16 when he or she starts to work) pyramid of China in 2040 based on the sixth census data and the predicted mortality probabilities.

4.2. The Actuarial Balance of the UEBEI Fund. Figure 4 shows the fund balance's forecast from 2020 to 2035. As shown, according to current assumptions, the trend that the annual fund expenditure is greater than the fund's revenue will occur in the UEBEI fund in 2025, with a fund gap of 141 billion yuan in that year and a fund gap of 9138.6 billion yuan in 2035. However, the cumulative pension fund pension has remained positive but will begin to decrease after 2030, but by 2035 there should be still 32736.4 billion. However, if the annual fund gap continues, the accumulated surplus will eventually be overdrawn.

Figure 5 shows the forecast of the fund balance under the pressure test considering the increase of the pension replacement rate by $5 \%$. According to this analysis, by 2021 , a fund gap of 3.1 billion yuan will start to occur in 2021, and the fund gap will reach 237.46 billion yuan and a cumulative deficit will be 511.16 billion yuan in 2030 .

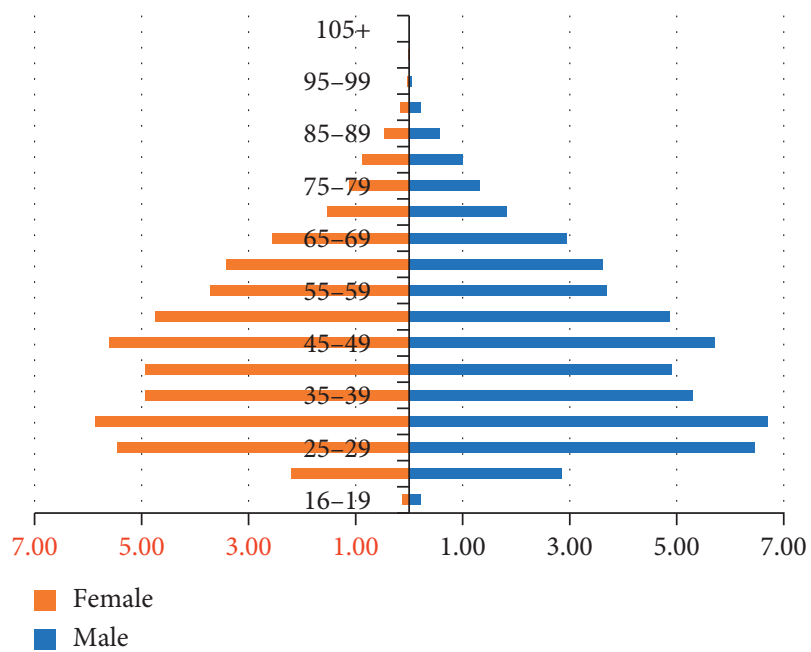

FIgure 3: The population pyramid of the UEBEI in 2040. Source: the authors performed calculation based on the model.

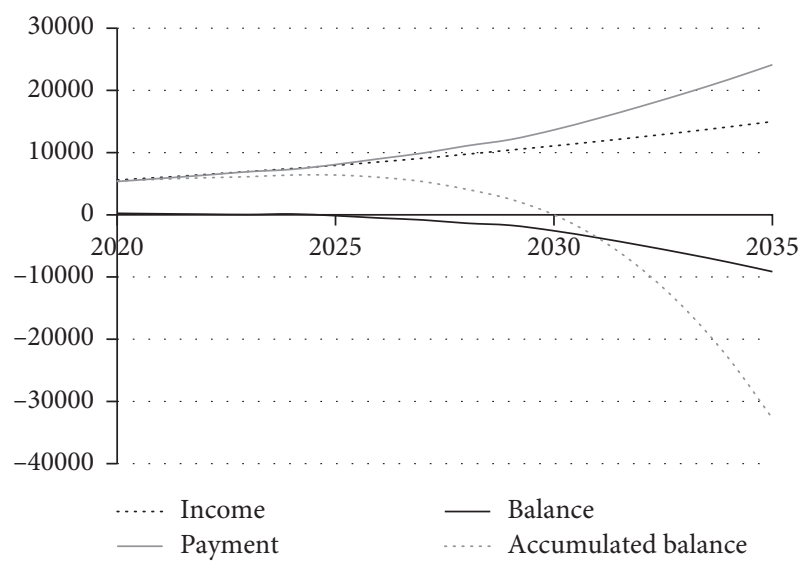

Figure 4: The forecast of the fund balance (in million yuan).

4.3. Analysis of the Factors Influencing the Balance of Revenue and Expenditure in the Model. Through the model analysis, we can see the influence of various factors on the balance of the model, as shown in Table 2.

Each variable in the model will affect the solvency of the insurance fund. There are several more important factors:

(1) Retirement age will affect how long people should work and how long retired workers can get their pension. Considering the impact on the pension fund's solvency, the higher the statutory retirement age is, the longer the employee's participation in UEBEI will be, the shorter the pension time will be, and the lesser the pressure on pension fund will be.

(2) The choice of pension replacement rate has a great impact on the operation of the UEBEI fund. Actually, this represents the "generosity" of the UEBEI system and measures the level of pension that retired workers receive. 


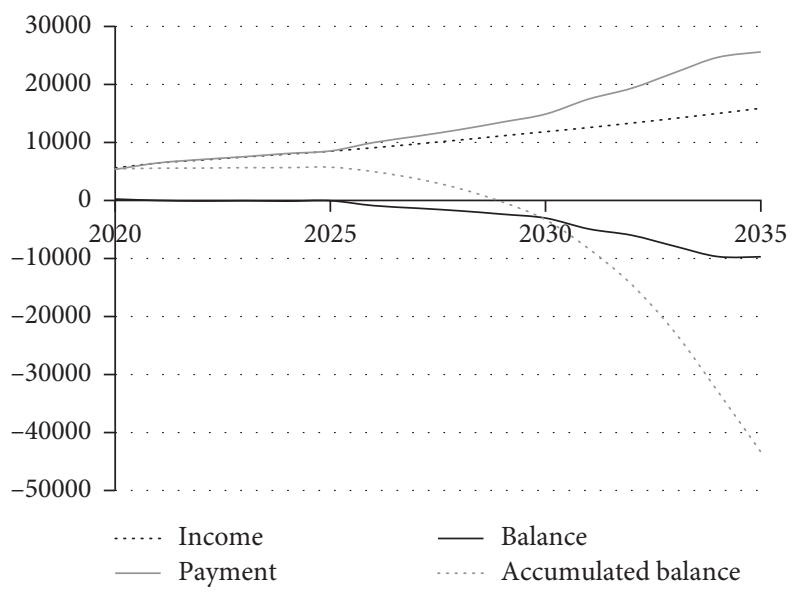

Figure 5: The forecast of the fund balance (the increase of the pension replacement rate by 5\%).

TABLE 2: The influence of various factors on the balance of income and expenditure of the model.

\begin{tabular}{|c|c|c|c|c|c|c|}
\hline & Collection rate & Investment yield & Payment rate & Substitution rate & Growth rate of wage & Age of retirement \\
\hline Influence direction & + & + & + & - & + & + \\
\hline
\end{tabular}

(3) As the management of individual account in China adopts the fully accumulated model, the individual account funds are directly related to the solvency of pension funds. Only when the yield rate on investment of the UEBEI fund is at least higher than the inflation rate at the same time, the actual social purchasing power of the fund will not depreciate and then the UEBEI fund may be able to maintain its value. This is also a key for the individual account fund to maintain its financial sustainability.

(4) Social dependency rate refers to the ratio of the number of retired workers who meet the conditions for receiving pensions to the total number of people employed in the society. China has a high dependency rate and has more employees in the primary industry. However, employees in the primary industry do not belong to the coverage of the UEBEI. Therefore, the number of retired workers who meet the conditions of receiving pensions accounts for a low proportion of the total social employment.

As can be seen from the scenario simulation, if the pension replacement rate increases by $5 \%$, the fund investment rate of return increases by $1 \%$, the collection rate increase by $10 \%$, the contribution rate increases by $1 \%$, the average retirement age is extended to 60 (Figure 6), or the fertility rate increases by $10 \%$ (Figure 7 ); the cumulative balance of pension funds can keep increasing and does not fall. However, all the annual balances will be negative in the future. That is to say, with the limited adjustment, the gap of the UEBEI fund in the future is inevitable. The influence of these five factors on the UEBEI fund is different. The effect of a $10 \%$ increase in the collection rate and a $1 \%$ increase in the

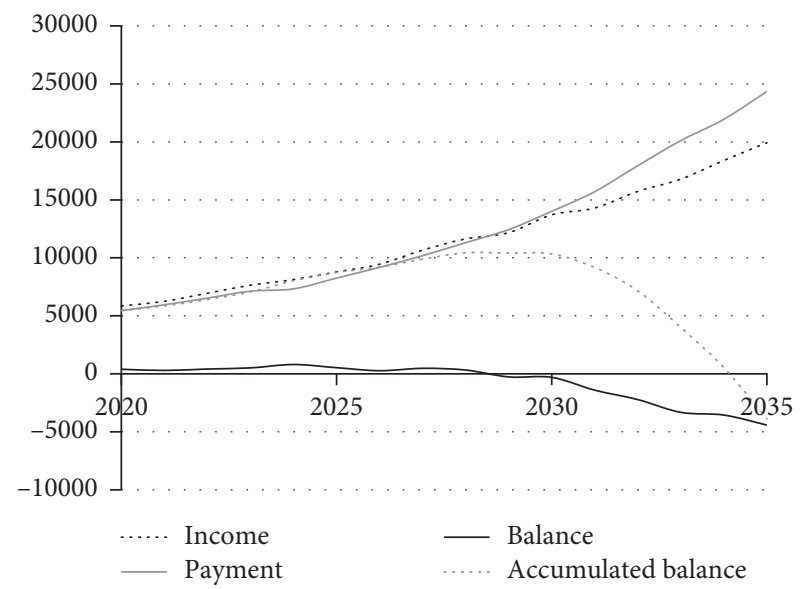

FIGURE 6: The forecast of the fund balance (the average retirement age is extended to 60 ).

contribution rate is not as big as a $1 \%$ increase in wage and delaying retirement.

The accumulated surplus gap is 3876 billion yuan by 2035 if retirement is delayed; the accumulated surplus gap is 22055 billion yuan by 2035 if the birth rate increases by $10 \%$. Thus, delayed retirement has a huge impact on the sustainable development of the accumulated surplus of the UEBEI. The effect of the fertility rate policy has been slowed down, but the effect of the delayed retirement has been very rapid.

As for substitution rate, raising the replacement rate by $5 \%$ will obviously make the revenue and expenditure of the UEBEI worse, and the fund expenditure will be significantly faster than the fund's revenue. The annual surplus will begin 


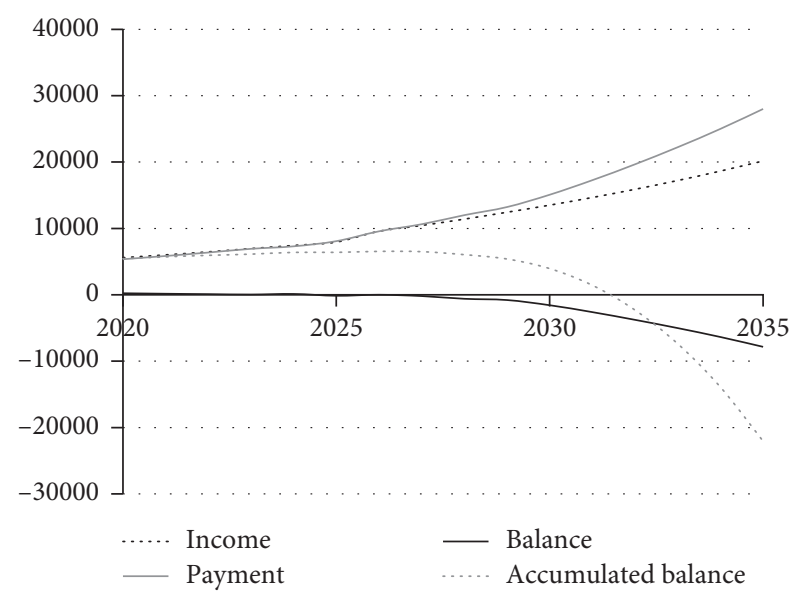

Figure 7: The forecast of the fund balance (the fertility rate increases by $10 \%)$.

to have a negative value in 2022 , and the accumulated surplus will also decrease at a faster rate after 2029, finally reaching 43162 billion yuan by 2035. In view of this, in the future, if we want to improve the treatment of retirees, it is very likely that state finances will fail to provide pensions. Retirees who want to maintain their quality of life after retirement will probably have to rely on their own ways.

\section{Concluding Remarks}

5.1. Conclusions. Based on the partial accumulation system of China's basic pension insurance fund, this paper constructs an actuarial balance model and then makes assumptions about each parameter in the model combined with the actual situation in China. Then, for people over 60, the most important population in the future demographic structure, we use the CBD model to make predictions. This is an innovation in this paper. Since the CBD model used in this paper constructs a dynamic mortality formula, it can predict the population structure of the super-elderly group and does not require the usage of truncated populations for older people. For example, for the pension insurance revenue and expenditure model, it is generally assumed that the ultimate survival age is 90 years. In this paper, in the dynamic mortality model, the mortality rate reaches 1 in the age of 150 , which is also different from the situation that the insurance industry directly cuts off at the age of 105 , and sets the mortality rate of the 105-year-old population as 1 . Moreover, through deductions of actual demographic data, China's ultimate survival age by 2030 can reach 113 . The introduction of the CBD model has solved the problem of super-elderly population structure and improved the accuracy of estimation.

According to the calculation of this paper, China's UEBEI fund income will begin to be less than the expenditure in the year of 2024. After that, the annual fund gap will have been continuing to increase to 2 trillion and 520 billion in 2030. The cumulative surplus of the fund will maintain a rapid growth firstly, up to 17 trillion and 970 billion. However, from 2029, the accumulated balance of the fund will begin to decrease from growth, which will decline to 16 trillion and 600 billion in 2030, and the trend of the further decline is obvious.

In addition, the paper also analyzes the factors that affect the balance of basic pension insurance. The increase of the wage growth rate due to social factors, the increase of fund investment yield, the delay of retirement, the increase of fund collection rate, and the reduction of pension replacement rate are all beneficial to the sustainability of the basic old-age insurance fund.

5.2. Policy Recommendations. From 1990s, since the World Bank has put forward the "three-pillar" model of the endowment insurance system, the upsurge of endowment insurance system reform has been raised worldwide. The reform can be divided into two aspects, structural reform and parametric reform. Structural reform refers to a fundamental change in the framework of the three-pillar model. Parameter reform means adjusting the factors affecting the endowment insurance system.

The decision made in 2015 has required Chinese institutions to establish occupational pension system, which is a compulsory payment item. However, its coverage is only 40 million public officers. It seems that China still needs to improve the establishment of enterprise annuity because private pension scheme has taken the leading position in many OECD countries. It has become the primary source of income for the elderly in some countries.

Over the past decade, almost all OECD countries have adjusted the relevant parameters of the pension system. Unlike the structural reform that has two significant stages, parametric reform has time continuity and content diversity.

From the perspective of the system of China's endowment insurance, the location and function of social mutual assistance programs and personal accounts in the first pillar of the UEBEI still need to be clarified. At present, there are no clear dividing lines for the use of the two account funds in China, and they can be adjusted with each other. In the new situation of population aging, the indicators related to individual accounts and projects of social mutual assistance programs, such as the rate of substitution and the rate of payment, still need to be further adjusted.

As for the second pillar, the enterprise annuity, according to the actual situation in China, the basic old-age insurance system security level is not limited to its original function of preventing the elderly from poverty. For many people, the basic pension insurance for the first pillar is the guarantee of their old life. The development of China's enterprise annuity has lagged behind, and the coverage and protection level have not been greatly improved. It has not played a role in raising the living standard of the elderly. At the same time, this situation restrains that the level of the basic pension insurance, as the first pillar, cannot be reduced, which will lead to too much financial burden on the government. Moreover, as the population aging situation intensifies, the financial burden of the government will increase further. 
Because of the early establishment of the OECD countries' public pension systems, they have been fully developed. So many OECD countries in this period mainly want to increase the coverage of private pension, and a few countries are committed to improving the coverage of compulsory pension insurance. As for China, although the coverage rate of enterprise annuity is very low, the top priority is to increase the coverage of basic pension insurance. The coverage rate of the UEBEI in China is about 63\%; that is, nearly $40 \%$ of the workers are not involved in basic pension insurance. In this aspect, Switzerland can be taken as an example, which has reduced the threshold of the pension plan to ensure that more part-time and low-income workers are included in the pension system.

Because China is a typical economic transition country, the present old-age security system is not perfect enough. Many urban and rural people who do not have formal jobs and some low-income groups have not been absorbed into the old-age insurance system. Expanding the coverage of pension insurance is conducive to increasing the income of endowment insurance fund, and the social insurance is based on the law of large numbers; the more the number of participants, the lower the risk, and the funds raised will also increase, which will help to dissolve the pressure of the rapid growth of the endowment insurance fund.

In the process of economic development, the retirement age in China has been unchanged for more than 50 years. In many countries, the retirement age is 5 years higher than that of China. The current retirement policy of China is obviously not suitable for the current economic development, and it will bring negative impact on the balance of pension fund.

In the case of increasing life expectancy in China, it is feasible to raise the retirement age, and it can also be seen from the calculation of the fifth chapter that the delay of retirement is very beneficial to the balance of the UEBEI fund. Compared with other OECD countries, China's current retirement age has a large space to be improved, and it can be implemented in a phased and gradual way.

5.3. Shortages and Prospects. The CBD model has better prediction results for the elderly population over 60 years of age, while for the population below 60 years of age, it is not ideal, so the empirical life table of China's insurance industry in 2003 is still used to predict the population structure between the ages of 21 and 59, while the data of this experience table may not reflect the current situation in China. In addition, this article does not study the population structure in terms of gender, which may lead to a certain error.

Therefore, it is hoped that there will be a better model to fit the mortality rate of the Chinese people in terms of age in the future, so that the future population structure of China can be better predicted. In addition, the current changes of the fertility policy in China will have a significant impact on the future fund balance. However, this article only studies the years to 2030, and the change of fertility policy will not affect the population structure of people taking part in work before 2030, but, in a longer period of time, the fertility policy will show its influence, so the follow-up study can be carried out in this aspect.

\section{Data Availability}

All data are available from National Bureau of Statistics at http://data.stats.gov.cn/easyquery.htm? $\mathrm{cn}=\mathrm{C} 01$.

\section{Conflicts of Interest}

The authors declare that they have no conflicts of interest.

\section{Acknowledgments}

This study was financially supported by the National Social Science Fund of China "research on the redistribution function of social security system: research on the national social security fund's intervention in pension insurance payment" and "the Fundamental Research Funds for the Central Universities” in UIBE (CXTD9-04).

\section{References}

[1] Z. Ren, Z. Luo, and W. Sun, China financial Report 2019: who will afford our retirement?, Evergrande Research Institute, Beijing, China, 2019, in Chinese.

[2] World Bank, Averting the Old Age Crisis-Policies to Protect the Old and Promote Growth, World Bank, Washington, DC, USA, 1994.

[3] J. Freedman and Y. Zhang, "China's pension paradoxes: challenges to creating an equitable and stable pension scheme," China: An International Journal, vol. 14, no. 3, pp. 153-166, 2016.

[4] Y. Tang, Y. Ruan, Y. Xu, and Y. Li, "Feedback analysis of population, economy and pension: moderate scale of China's pension strategic reserve," Physica A-Statistical Mechanics and Its Applications, vol. 12, pp. 40-43, 2020.

[5] L. R. Carter and R. D. Lee, "Modeling and forecasting US sex differentials in mortality," International Journal of Forecasting, vol. 8, no. 3, pp. 393-411, 1992.

[6] A. E. Renshaw and S. Haberman, "A cohort-based extension to the Lee-Carter model for mortality reduction factors," Insurance: Mathematics and Economics, vol. 38, no. 3, pp. 556-570, 2006.

[7] E. N. Reither, R. K. Masters, Y. C. Yang, D. A. Powers, H. Zheng, and K. C. Land, "Should age-period-cohort studies return to the methodologies of the 1970s?" Social Science \& Medicine, vol. 128, pp. 356-365, 2015.

[8] D. Hainaut, "Multidimensional Lee-Carter model with switching mortality processes," Insurance: Mathematics and Economics, vol. 50, no. 2, pp. 236-246, 2012.

[9] A. Bell, "Life-course and cohort trajectories of mental health in the UK, 1991-2008 - a multilevel age-period-cohort analysis," Social Science \& Medicine, vol. 120, pp. 21-30, 2014.

[10] A. J. G. Cairns, D. Blake, and K. Dowd, "A two-factor model for stochastic mortality with parameter uncertainty: theory and calibration," Journal of Risk \& Insurance, vol. 73, no. 4, pp. 687-718, 2006.

[11] A. J. G. Cairns, D. Blake, K. Dowd, G. Coughlan, and D. Epstein, "A quantitative comparison of stochastic mortality models using data from England \& Wales and the United 
States," North American Actuarial Journal, vol. 13, no. 1, pp. 1-35, 2007.

[12] A. J. G. Cairns, D. Blake, K. Dowd, G. D. Coughlan, D. Epstein, and M. Khalaf-Allah, "Mortality density forecasts: an analysis of six stochastic mortality models," Insurance: Mathematics and Economics, vol. 48, no. 3, pp. 355-367, 2011.

[13] M. F. Carfora, L. Cutillo, and A. Orlando, "A quantitative comparison of stochastic mortality models on Italian population data," Computational Statistics \& Data Analysis, vol. 112, pp. 198-214, 2017.

[14] P. Chernyavskiy, M. P. Little, and P. S. Rosenberg, “A unified approach for assessing heterogeneity in age-period-cohort model parameters using random effects," Statistical Methods in Medical Research, vol. 28, no. 1, pp. 20-34, 2019.

[15] Y. T. Xie and Z. X. Li, "Extension of bonus-malus factor based on joint pricing models," Statistics \& Information Forum, vol. 30, no. 6, pp. 33-39, 2015, in Chinese.

[16] S. Basnayake and L. Nawarathna, "Modeling and forecasting Norway mortality rates using the Lee-carter model," Journal of Biometrics \& Biostatistics, vol. 6, no. 1, 2017.

[17] R. Giacometti, M. Bertocchi, S. T. Rachev, and F. J. Fabozzi, "A comparison of the Lee-carter model and AR-ARCH model for forecasting mortality rates," Insurance: Mathematics and Economics, vol. 50, no. 1, pp. 85-93, 2012.

[18] F. Zhu and Y. Yang, "Based on the improved Leslie matrix gray model of the population precast," Information Technology, vol. 5, pp. 12-15, 2016.

[19] Y. Xie, H. Yu, X. Lei, and A. Lin, "The impact of fertility policy on the actuarial balance of China's urban employee basic medical insurance fund-the selective two-child policy vs. the universal two-child policy," North American Journal of Economics and Finance, 2020.

[20] I. Mircea, M. Covrig, and R. Serban, "Some mathematical models for longevity risk in the annuity market and pension funds," Procedia Economics and Finance, vol. 15, pp. 115-122, 2014.

[21] T. Lin and C. C.-L. Tsai, "On the mortality/longevity risk hedging with mortality immunization," Insurance: Mathematics and Economics, vol. 53, no. 3, pp. 580-596, 2013.

[22] W. Yu, P. Guo, Q. Wang et al., "On a periodic capital injection and barrier dividend strategy in the compound Poisson risk model," Mathematics, vol. 8, no. 4, p. 511, 2020.

[23] C. Metzger, "An actuarial balance sheet of the Swiss old-age pension scheme," International Social Security Review, vol. 71, no. 1, pp. 25-49, 2018.

[24] R. Meyricke and M. Sherris, "Longevity risk, cost of capital and hedging for life insurers under Solvency II," Insurance: Mathematics and Economics, vol. 55, no. 1, pp. 147-155, 2014.

[25] N. Bosnjak, "The actuarial projection method for pension fund's dependency ratio in case of Pension and Disability Insurance Fund of Republic of Srpska," New Challenges of Official and Applied Statistics in European Union, vol. 1, no. 1, pp. 72-78, 2016.

[26] A. A. Belolipetskii and M. A. Lepskaya, "A mathematical model of pension fund operation and methods of fund stability analysis," Computational Mathematics and Modeling, vol. 29, no. 2, pp. 233-243, 2018.

[27] Z. Q. Luo, Z. Y. Chen, and A. Lu, "A study on the effects of population factors on the payment balance of basic pension insurance funds in China," Forecasting, vol. 29, no. 2, pp. 42-46, 2010.

[28] W. Yu, F. Wang, Y. Huang, and H. Liu, "Social optimal mean field control problem for population growth model," Asian Journal of Control, vol. 2019, pp. 1-8, 2019.
[29] C. Q. Wang, Y. Tian, and H. Y. Xue, "Calculation on the fund balance of urban workers' basic old-age insurance: 2016-2060 - based on the dual study of fertility policy adjustments and delaying retirement," Reform of Economic System, vol. 2017, no. 4, pp. 27-34, 2017.

[30] C. Cong and W. Jin, "The primary endowment insurance contribution mechanism: research on the effect of the longterm balance of endowment insurance fund," Social Security Studies, vol. 4, pp. 3-13, 2017.

[31] Y. Y. He and G. C. Liu, "A two factor state-space model for stochastic mortality and longevity risk measurement," Theory \& Practice of Finance \& Economic, vol. 35, no. 5, pp. 24-28, 2014.

[32] X. J. Wang and S. L. Huang, "Comparison and selection of stochastic mortality models in China," Population \& Economics, vol. 1, pp. 82-86, 2011.

[33] L. Yuan and H. Pan, "Research on measurement of longevity risk of pension system: a projection of the population mortality in China based on Lee-carter model," Labor Economic Review, vol. 9, no. 2, pp. 70-84, 2016.

[34] J. H. Cui and Y. T. Xie, "Regional income mobility of urban households, tax burden, and dynamic equilibrium of income distribution," Journal of Finance and Economics, vol. 43, no. 8, pp. 43-55, 2017.

[35] J. H. Cui, W. F. Li, and Y. T. Xie, "Does decision-making of grassroots fiscal expenditure favour the poor? Evidence from tracking investigation of the Chinese countryside families," Finance \& Trade Economics, vol. 39, no. 2, pp. 21-35, 2018.

[36] Y. Zeng, C. R. Ren, and Q. Liu, "Will extending the retirement age improve the solvency of China's pension insurance? Simulation analysis based on actuarial models," Economic Management Journal, vol. 35, no. 5, pp. 108-117, 2013.

[37] Y. Q. Zhao, M. Y. Bai, Y. L. Liu, and J. Z. Hao, "Quantitative analyses of transition pension liabilities and solvency sustainability in China," Sustainability, vol. 9, no. 12, pp. 22-52, 2017.

[38] T. Abdessalem and H. Chekki Cherni, "Macroeconomic effects of pension reforms in the context of aging populations: overlapping generations model simulations for Tunisia," Middle East Development Journal, vol. 8, no. 1, pp. 84-108, 2016.

[39] P. Müller and J. Wagner, "The impact of pension funding mechanisms on the stability and payoff from Swiss DC pension schemes: a sensitivity analysis," The Geneva Papers on Risk and Insurance - Issues and Practice, vol. 42, no. 3, pp. 423-452, 2017. 